\title{
Suppressive Effect of Quercetin on Nitric Oxide Production from Nasal Epithelial Cells In Vitro
}

\author{
Nachi Ebihara, ${ }^{1}$ Kana Takahashi, ${ }^{1}$ Haruka Takemura, ${ }^{1}$ Yuko Akanuma, \\ Kazuhito Asano $\left(\mathbb{1}^{2},{ }^{2}\right.$ and Masataka Sunagawa $\oplus^{1}$ \\ ${ }^{1}$ Department of Physiology, School of Medicine, Showa University, Tokyo, Japan \\ ${ }^{2}$ Division of Physiology, School of Nursing and Rehabilitation Sciences, Showa University, Yokohama, Japan \\ Correspondence should be addressed to Kazuhito Asano; asanok@med.showa-u.ac.jp
}

Received 23 January 2018; Revised 19 March 2018; Accepted 7 June 2018; Published 5 July 2018

Academic Editor: Junji Xu

Copyright (C) 2018 Nachi Ebihara et al. This is an open access article distributed under the Creative Commons Attribution License, which permits unrestricted use, distribution, and reproduction in any medium, provided the original work is properly cited.

Nitric oxide (NO) is known to play pivotal roles as one of the final effector molecules in the development of allergic diseases, including allergic rhinitis (AR). Although quercetin has been reported to attenuate the clinical conditions of AR, its influence on NO production is not well defined. The present study aimed to examine the influence of quercetin on in vitro NO production from nasal epithelial cells after interleukin- (IL-) 4 stimulation. Human nasal epithelial cells (HNEpCs) at a concentration of $1 \times 10^{5}$ cells $/ \mathrm{ml}$ were stimulated with $10.0 \mathrm{ng} / \mathrm{ml}$ of IL- 4 in the presence and absence of quercetin. After 48 hours, the culture supernatants were collected and assayed for $\mathrm{NO}\left(\mathrm{NO}_{2}\right.$ and $\left.\mathrm{NO}_{3}\right)$ using the Griess method. The influences of quercetin on the transcription factor, STAT6, activation, and iNOS mRNA expression were also examined using ELISA and real-time quantitative RT-PCR, respectively. Addition of quercetin to cell cultures caused suppression of NO production from HNEpCs after IL-4 stimulation. The minimum concentration of quercetin that caused significant suppression was $1.0 \mathrm{nM}$. Treatment of cells with quercetin at more than $1.0 \mathrm{nM}$ suppressed STAT6 activation and iNOS mRNA expression induced by IL-4 stimulation. The present results strongly suggested that quercetin favorably modified the clinical condition of AR through the suppression of NO production from nasal epithelial cells after IL-4 stimulation.

\section{Introduction}

Allergic rhinitis (AR) is a chronic inflammatory condition of the nasal mucosa in sensitized patients and is mediated by IgE-dependent immune responses to several types of environmental allergens, such as pollen, house dust, and animal dander. After inhalation, these allergens are internalized and processed by antigen presenting cells, especially dendritic cells and macrophages, and the peptide fragments of these allergens are presented to Th2-type helper $\mathrm{T}$ cells $[1,2]$. Activated Th2-type helper T cells secrete interleukin- (IL-) 4 and IL-13, which trigger the production of antigen-specific IgE from B cells. The produced antigen-specific IgE binds to high-affinity receptors for $\operatorname{IgE}(\mathrm{Fc \varepsilon R})$ that are expressed on the surface of mast cells. When the specific allergen is reinhaled into the nose, the adjacent IgE molecules cross, and mast cell degranulation occurs, which causes the release of a wide variety of chemical mediators such as histamine, leukotriene, and prostaglandins $[1,2]$. These mediators cause the cardinal symptoms of $\mathrm{AR}$, including sneezing, nasal itching, and nasal congestion $[1,2]$. All these reactions occur within minutes after allergen exposure and are referred to as early phase responses $[1,2]$. Over 4 to 6 hours after allergen exposure, these mediators, through a complex interplay of several types of events, trigger the recruitment and accumulation of inflammatory cells such as eosinophils, $\mathrm{T}$ cells, and mast cells in the nasal mucosa, resulting in the persistent allergic inflammation and the symptoms associated with nasal congestion [1-3]. These responses are referred to as late phase responses and are mainly mediated by eosinophils via the secretion of factors, such as eosinophil cationic protein, major basic protein, and leukotrienes, among others, which cause persistent inflammation and epithelial damage in the nasal mucosa $[1,4]$. In addition to these chemical mediators, eosinophils produce free radicals such as $\mathrm{O}_{2}{ }^{-}$and $\mathrm{H}_{2} \mathrm{O}_{2}$ [5]. 
Nitric oxide (NO) was first identified as a vasodilator and is considered a key gaseous signaling molecule that plays a role in a variety of normal physiological processes, following the induction of endothelial nitric oxide synthase (eNOS) and neuronal NOS (nNOS) [6,7]. On the other hand, the amount of NO produced by inducible NOS (iNOS) from polymorphonuclear leukocytes, such as neutrophils, eosinophils, mast cells, epithelial cells, and fibroblasts after inflammatory stimulation is generally larger than that produced by eNOS and nNOS; moreover, NO causes the oxidation of the components of the cell membrane and tissue injury in the presence of superoxide [7-9]. In patients with $A R$, some studies have shown increased levels of both iNOS in the nasal mucosa [10] and NO in exhaled air [11-13], suggesting that NO may play an essential role in the development of chronic AR $[12,14]$.

Quercetin is one of the plant-derived polyphenolic compounds, called flavonoids, which are found in a variety of human diets [15]. Several studies on the beneficial effects of quercetin on human health revealed that it has antimicrobial, anticancer, antidiabetic, and antihypertensive activities [1618]. Quercetin has also been shown to act as a scavenger of free radicals and to protect the development of oxidative stress responses [19]. In allergic diseases, quercetin has been reported to inhibit the production of inflammatory cytokines, chemokines, and chemical mediators from mast cells and eosinophils in vitro [20-23]. Additionally, studies involving experimental murine and rat models of allergy have shown that oral administration of quercetin inhibited the development of allergic symptoms, such as bronchial hyperreactions, scratching, rubbing around the nose, and cyanosis around the tail after a specific allergen challenge [24, 25]. A previous study involving AR model rats showed that quercetin attenuated the clinical symptoms of sneezing and nasal rubbing movements through the suppression of substance $\mathrm{P}$, calcitonin gene-related peptide, and nerve growth factor in the nasal cavity after nasal challenge with toluene diisocyanate [26]. However, the influence of quercetin on NO production has not been sufficiently investigated. Therefore, the present study aimed to assess the influence of quercetin on NO production in vitro.

\section{Materials and Methods}

2.1. Reagents. Quercetin was purchased from Sigma-Aldrich Co., Ltd. (St. Louis, MO, USA) as a preservative-free pure powder. It was dissolved in dimethyl sulfoxide (DMSO) at a concentration of $10.0 \mathrm{mM}$ and was then diluted with Airway Epithelial Cell Growth Media (AECG medium; PromoCell $\mathrm{GmbH}$, Heidelberg, Germany) at appropriate concentrations for the experiments, sterilized by passing through $0.2 \mu \mathrm{m}$ filters, and stored at $4^{\circ} \mathrm{C}$ until use. Recombinant human IL4 was purchased from R \& D Systems, Inc. (Minneapolis, $\mathrm{MN}$, USA), as a preservative-free pure powder. IL-4 was also dissolved in an AECG medium, then sterilized, and stored at $4^{\circ} \mathrm{C}$ until use. Leflunomide, which is a Janus kinase (JAK)-STAT6 inhibitor [27, 28], was purchased from Sigma-Aldrich Co., Ltd., and was first dissolved in DMSO at a concentration of $1.0 \mathrm{mg} / \mathrm{ml}$. This was followed by dilution in an AECG medium at appropriate concentrations for the experiments. mRNA isolation kits were purchased from Milteny Biotec (Bergisch Gladbach, Germany). The reagents used for the cDNA synthesis and quantitative realtime reverse transcription-polymerase chain reaction (RTPCR; TaqMan Gene Expression Assays) kit were purchased from Invitrogen Corp. (Carlsbad, CA, USA) and Applied Biosystems (Foster City, CA, USA), respectively.

2.2. Cell Culture. Human nasal epithelial cells (HNEpCs), which were established by PromoCell $\mathrm{GmbH}$, were suspended in an AECG medium (PromoCell $\mathrm{GmbH}$ ) at a concentration of $1 \times 10^{5}$ cells $/ \mathrm{ml}$, and were used as a target. To examine the influence of IL-4 on NO production from HNEpCs, $1 \times 10^{5}$ cells $(1.0 \mathrm{ml})$ were introduced in triplicate into 24-well culture plates containing various concentrations $(0.5$ to $30.0 \mathrm{ng} / \mathrm{ml})$ of IL- 4 to make a final volume of $2.0 \mathrm{ml}$. After 24 to 72 hours, the culture supernatants were collected and stored at $-40^{\circ} \mathrm{C}$ until use. To examine the influence of quercetin and leflunomide on $\mathrm{NO}$ production from HNEpCs after IL-4 stimulation, $1 \times 10^{5}$ cells $(1.0 \mathrm{ml})$ were introduced in triplicate into 24 -well culture plates containing various concentrations of either quercetin or leflunomide. The cells were then stimulated with $10.0 \mathrm{ng} / \mathrm{ml}$ of IL- 4 for 48 hours in a solution with a total volume of $2.0 \mathrm{ml}$. The culture supernatants were collected and stored as mentioned above. To examine the influence of quercetin on the transcription factor, STAT6, activation, and iNOS mRNA expression in HNEpCs, $1 \times 10^{5}$ cells were cultured in a similar manner for 12 and 24 hours, respectively [29]. In all experiments, quercetin and leflunomide were added to cell cultures 2 hours before stimulation.

2.3. Assay for NO. The NO levels in the culture supernatants were examined in duplicate using commercially available Griess reagent kits, which can measure $\mathrm{NO}_{2}$ and $\mathrm{NO}_{3}$ (Dojin Co., Ltd., Kumamoto, Japan), according to the manufacturer's recommended procedures.

2.4. Assay for Radical Intensity. The NO-scavenging activity of quercetin was examined using an electron spin resonance (ESR) spectrometer (JOEL JES RE1X, X-band, $100 \mathrm{kHz}$ modulation frequency; JOEL Datum Co., Tokyo, Japan), according to the methods described previously [30]. The radical intensity of $\mathrm{NO}$, which was produced from a reaction mixture of $20 \mu \mathrm{M}$ carboxy-PTIO and $60 \mu \mathrm{M}$ NOC-7, was determined in a $0.1 \mathrm{M}$ phosphate buffer $(\mathrm{pH} 7.4)$ in the presence of $30 \%$ DMSO. Samples were added after $3 \mathrm{~min}$ of mixing the reagents. The reaction mixture was then introduced into a capillary (100 x $1.1 \mathrm{~mm}$ ID, Drummond Scientific Co., Broomall, PA, USA), which was placed in a quartz cell (270 mm long, $5 \mathrm{~mm}$ ID, JOEL Datum Co.). The ESR signal was measured at resonance frequency of $9.4 \mathrm{GHz}$ under the following conditions: center field, $336.0 \pm 5.0 \mathrm{mT}$; microwave power $8 \mathrm{~mW}$; modulation amplitude, $0.1 \mathrm{mT}$; gain, 250; scan time, 2 min and time constant, 0.03. The radical intensity of NO was defined as the ratio of the signal intensity of the first peak of carboxy-PTIO to that of $\mathrm{MnO}$, and it was expressed relative to the height of $\mathrm{MnO}$, which was an external marker. 
2.5. Assay for Transcription Factor Activation. STAT6 activity in the cultured cells was examined by measuring the phosphorylated STAT6 level using commercially available ELISA test kits (Abcam plc., Cambridge, MA, USA), according to the manufacturer's recommended procedures.

2.6. Qualitative Assay for mRNA Expression. mRNA expression for iNOS in the cultured cells was examined by quantitative real-time RT-PCR. Total mRNA was isolated from the cultured cells using mRNA isolation kit (Milteny Biotec), according to the manufacturer's protocols. First-strand cDNA was synthesized from $2.0 \mu \mathrm{g}$ of mRNA using a Superscript cDNA synthesis kit (Invitrogen Corp.), according to the manufacturer's instructions with a T100 thermal cycler (BioRad Co., Hercules, CA, USA). The cDNA templates were then amplified by PCR using TaqMan Gene Expression Assays, PCR primers (iNOS; TaqMan Gene Expression Assays; No. Hs01075529_ml and GAPDH; TaqMan Gene Expression Assays; No. Hs02786624_gl) and RT master mix. Predesigned and validated gene-specific TaqMan Gene Expression Assays $[31,32]$ were used in duplicate for quantitative real-time RTPCR, according to the manufacturer's protocols. PCR assays were conducted as follows: denaturation at $95^{\circ} \mathrm{C}$ for $10 \mathrm{~min}$, 40 cycles of $15 \mathrm{~s}$ denaturation at $95^{\circ} \mathrm{C}$, and $1 \mathrm{~min}$ annealing and extension at $60^{\circ} \mathrm{C}$. The samples were analyzed using the $\mathrm{ABI}$ Prism 7900HT Fast RT-PCR System (Applied Biosystems) [32]. Relative quantification (RQ) studies [33] were prepared from the data collected [threshold cycle numbers $(\mathrm{Ct})$ ] with the ABI Prism 7900HT Sequence-Detection System (SDS) software v. 2.3 (Applied Biosystems).

2.7. Statistical Analysis. Significant statistical differences between the control and experimental groups were examined using ANOVA followed by Dunnette's multiple comparison test. Data analysis was performed using ANOVA for Mac (SPSS Inc., Chicago, IL, USA). The level of significance was considered at a $\mathrm{P}$ value of $<0.05$.

\section{Results}

3.1. Influence of Quercetin on NO Production from HNEpCs after IL-4 Stimulation. The first set of experiments showed that IL-4 stimulation caused an increase in NO production from HNEpCs, which was first observed at $0.5 \mathrm{ng} / \mathrm{ml}$ and peaked at more than $10.0 \mathrm{ng} / \mathrm{ml}$ of IL-4 (Figure 1(a)). The second set of experiments on the time course of NO production from HNEpCs in response to IL-4 stimulation showed that the NO levels peaked at 48 hours and plateaued thereafter (Figure 1(b)). The third set of experiments showed that although treatment of cells with quercetin at $100.0 \mathrm{pM}$ did not inhibit NO production from HNEpCs, quercetin at 1.0 $\mathrm{nM}$ significantly suppressed the ability of cells to produce NO in response to IL-4 stimulation. The NO levels in the culture supernatants were nearly identical between the experimental and control groups, but this was not significant (Figure 2). Furthermore, the addition of quercetin at more than 5.0 $\mathrm{nM}$ into the cell cultures completely inhibited the ability of the cells to produce NO after IL- 4 stimulation. The NO levels in the culture supernatants were extremely lower in the experimental samples than in the control samples (Med. alone; Figure 2).

3.2. NO-Scavenging Activity of Quercetin. In ESR study (Figure 3), the NO radical produced by NOC-7 could not scavenged by quercetin at $100.0 \mathrm{pM}$, was significantly scavenged by quercetin at $1.0 \mathrm{nM}$, and was completely scavenged by quercetin at more than $100.0 \mathrm{nM}$.

3.3. Influence of Quercetin on STAT6 Activation and iNOS mRNA Expression in HNEpCs after IL-4 Stimulation. The IL4 -induced increase in NO production from HNEpCs was significantly suppressed by leflunomide at more than 75.0 $\mathrm{ng} / \mathrm{ml}$ but not at less than $50.0 \mathrm{ng} / \mathrm{ml}$ (Figure 4). We next examined the influence of quercetin on STAT6 activation in HNEpCs after IL-4 stimulation. Addition of quercetin into the cell cultures at more than $1.0 \mathrm{nM}$ caused significant suppression of the IL-4-induced STAT6 activation (Figure 5). Finally, treatment of cells with quercetin at more than 1.0 $\mathrm{nM}$ caused significant suppression of the IL-4-induced iNOS mRNA expression in HNEpCs (Figure 6).

\section{Discussion}

The present study showed that quercetin, at minimum concentration of $1.0 \mathrm{nM}$, significantly inhibited IL-4-induced NO production from nasal epithelial cells through the suppression of STAT6 activation and iNOS mRNA expression. A previous study reported that, after oral administration of $64 \mathrm{mg}$ quercetin to healthy humans, the plasma levels of quercetin gradually increased, peaked at $650 \mathrm{nM}$, and decreased to half the peak levels at 24 hours after administration [34]. A dose of $1200 \mathrm{mg}$ quercetin per day is recommended as a dietary supplement that can increase the plasma quercetin concentration to up to $12 \mu \mathrm{M}$ [34], which is much higher than the level that suppressed NO production in vitro. Based on these reports, it is strongly suggested that the results obtained in this study may reflect the in vivo effect of quercetin on NO production from nasal epithelial cells after inflammatory stimulation.

Polymorphonuclear leukocytes, including eosinophils and mast cells, are known to play pivotal roles in the development of allergic inflammatory responses through the secretion of inflammatory cytokines and chemical mediators [1-4]. In addition to these mediators, polymorphonuclear leukocytes can produce reactive oxygen species, such as $\mathrm{O}_{2}{ }^{-}$ and $\mathrm{H}_{2} \mathrm{O}_{2}$, which are responsible for the modification of inflammatory responses [5]. Another reactive oxygen species, which is NO, is also produced by these inflammatory cells [7-9] and plays essential roles as one of the final effector molecules in the pathogenesis of inflammatory responses $[12,14]$. NO is generated by several types of mammalian cells and is rapidly oxidized to its more stable metabolites, including nitrite and nitrate. These metabolites react with superoxide to produce the damaging oxidant peroxynitrite, which initiates the oxidation of proteins and lipids in the outer cell membrane, and result in the development of tissue injury [7-9]. The NO that does not completely form peroxynitrite can easily penetrate the cell membrane and react with 




(a)

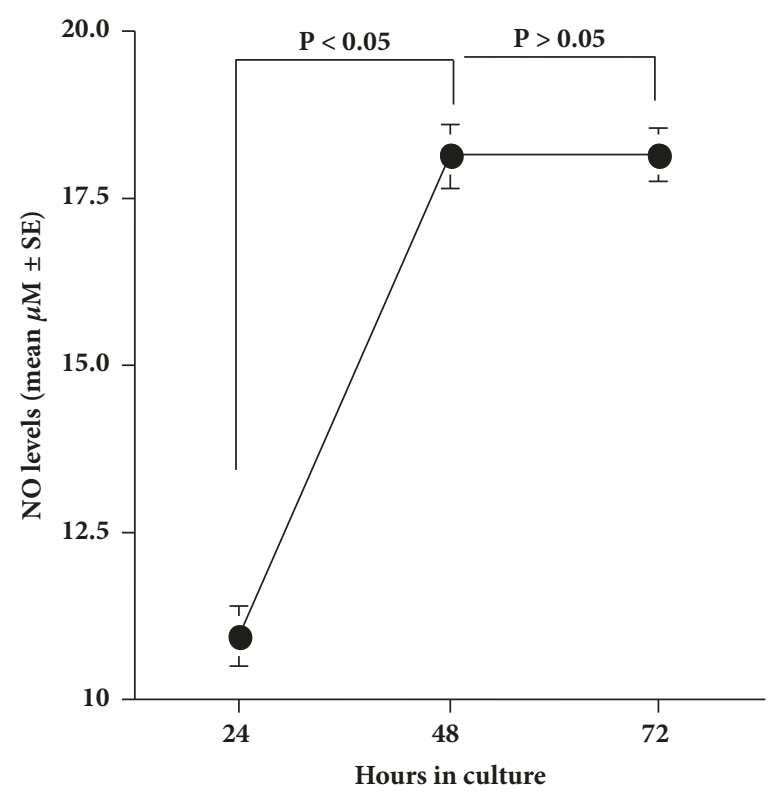

(b)

FIGURE 1: Influence of IL-4 stimulation on NO production from HNEpCs in vitro. HNEpCs at $1 \times 10^{5}$ cells/ml are stimulated with different concentrations of IL- 4 for 24 to 72 hours. NO levels in the culture supernatants are measured using the Griess method, and the results are expressed as the mean $\mu \mathrm{M} \pm \mathrm{SE}$ of the triplicate cultures. (a) Dose-response profile of IL-4 on NO production; (b) time course of IL-4-induced NO production. The experiments are performed twice with similar results. Med. alone: medium alone; IL-4: interleukin-4; NO: nitric oxide; HNEpCs: human nasal epithelial cells.

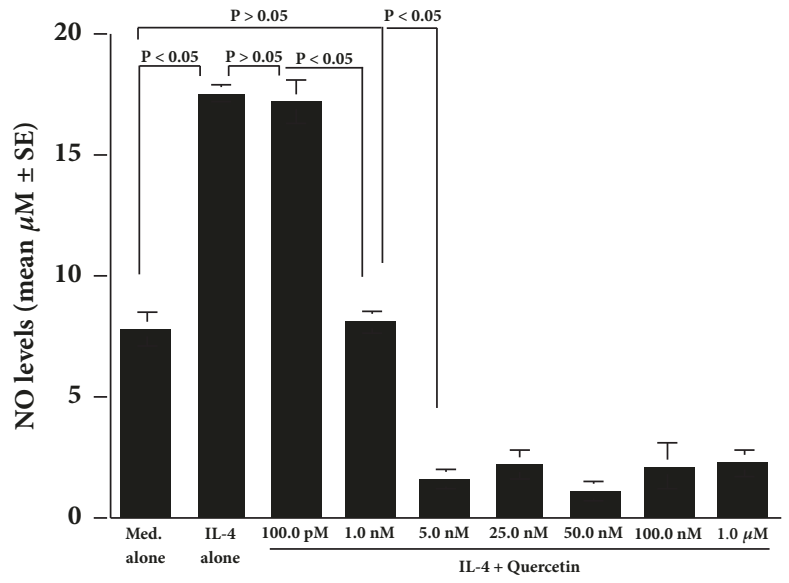

FIGURE 2: Influence of quercetin on NO production from HNEpCs after IL-4 stimulation in vitro. HNEpCs at $1 \times 10^{5}$ cells/ml are cultured with $10.0 \mathrm{ng} / \mathrm{ml}$ of IL- 4 for 48 hours in the presence and absence of various concentrations of quercetin. The NO levels in the culture supernatants are measured using the Griess method, and the results are expressed as the mean $\mu \mathrm{M} \pm \mathrm{SE}$ of the triplicate cultures. The experiments are performed twice with similar results. Med. alone: medium alone; IL-4: interleukin-4; NO: nitric oxide; HNEpCs: human nasal epithelial cells.

intracellular superoxide to form peroxynitrite, which causes nuclear membrane and DNA damage and apoptotic cell death in inflammatory tissues [7-9]. To clarify the relationship between the changes in $\mathrm{NO}$ and $\mathrm{AR}$ development, some researchers reported that the NO levels in the exhaled air were higher in AR patients than in healthy controls [1114]. NO levels have been found to correlate positively with the computed tomography findings in AR patients [12], and a high nasal NO level might be a useful biomarker of eosinophilic inflammation that is indicative of $\mathrm{AR}$ in the nasal mucosa $[13,14]$. Along with these findings, the results of the present study indicated that the suppressive effect of quercetin on NO production from nasal epithelial cells might be one of the therapeutic mechanisms of quercetin in AR.

IL-4, which is an immunoregulatory cytokine that is produced predominantly by Th2 type $\mathrm{T}$ cells, is well known to play essential roles in the class switching to $\operatorname{IgE}$ among $\mathrm{B}$ cells and in the maturation of Th2 T cells, which are 


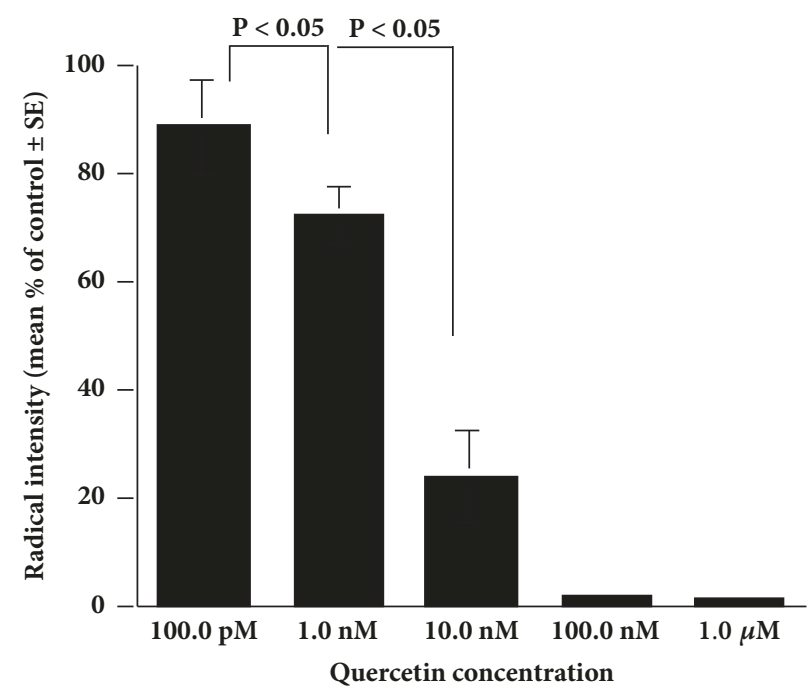

FIGURE 3: Nitric oxide scavenging activity of quercetin in vitro. The reaction mixture of various concentrations of quercetin, NOR-7, and carboxy-PTIO is prepared in phosphate buffer and incubated at $25^{\circ} \mathrm{C}$ for 30 minutes. Radical intensity is measured with an ESR spectrometer. The experiments are performed twice with similar results.

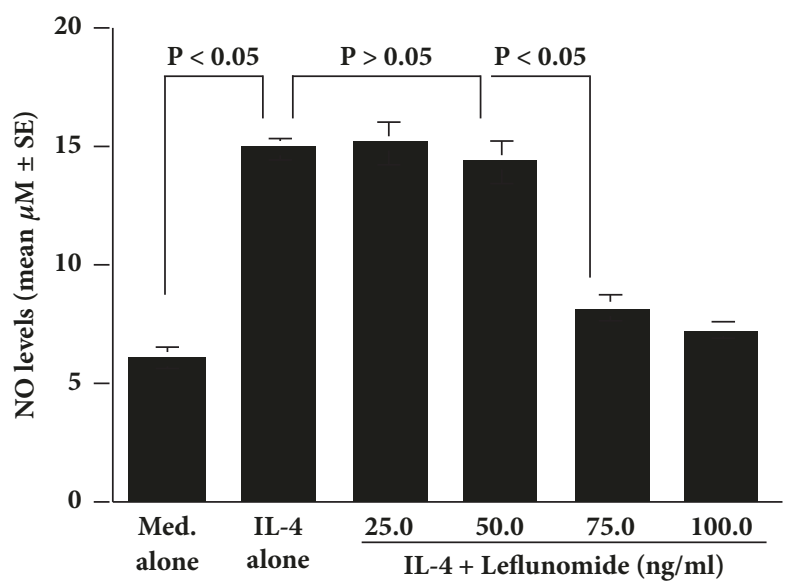

FIGURE 4: Influence of leflunomide on IL-4-induced NO production from HNEpCs in vitro. HNEpCs at $1 \times 10^{5}$ cells/ml are cultured with 10.0 $\mathrm{ng} / \mathrm{ml}$ of IL-4 for 48 hours in the presence and absence of various concentrations of leflunomide. The NO levels in the culture supernatants are measured using the Griess method, and the results are expressed as the mean $\mu \mathrm{M} \pm \mathrm{SE}$ of the triplicate cultures. The experiments are performed twice with similar results. Med. alone: medium alone; IL-4: interleukin-4; NO: nitric oxide; HNEpCs: human nasal epithelial cells.

responsible for the development and persistence of allergic diseases, including AR $[35,36]$. IL-4 mediates its functions by interacting with complex receptor systems, including type I and type II receptor systems [36]. IL-4 first attaches to the alpha subunit of the IL- 4 receptor, and this complex induces the activation of the tyrosine kinases, JAK 1 and JAK 3, which cause the phosphorylation of the transcription factor, STAT6 $[36,37]$. Phosphorylated STAT6 then migrates to the nucleus and binds to the promoter regions of IL- 4 responsive genes, resulting in the mRNA expression that is essential for the production of inflammatory mediators, including NO [34]. Therefore, the second part of the experiments was undertaken to examine whether quercetin could inhibit NO production from nasal epithelial cells after IL-4 stimulation through the suppression of this signaling pathway. The present results showed that treatment of nasal epithelial cells with leflunomide at more than $75.0 \mathrm{ng} / \mathrm{ml}$ caused significant inhibition of IL-4-induced NO production. Leflunomide was reported to inhibit the tyrosine phosphorylation of both JAK3 and STAT6 $[27,28]$. Activation of JAK3 was also reported to correlate with the tyrosine phosphorylation of STAT6 [27]. From these reports, the present results strongly suggested that the JAK/STAT signaling pathway is essential for NO production from nasal epithelial cells after IL-4 stimulation and that quercetin inhibits IL-4-induced NO production from nasal epithelial cells through the suppression of this signaling pathway, especially STAT6 activation. This speculation might be supported in part by the present findings that IL-4induced STAT6 activation and iNOS mRNA expression were significantly suppressed by treatment of nasal epithelial cells 


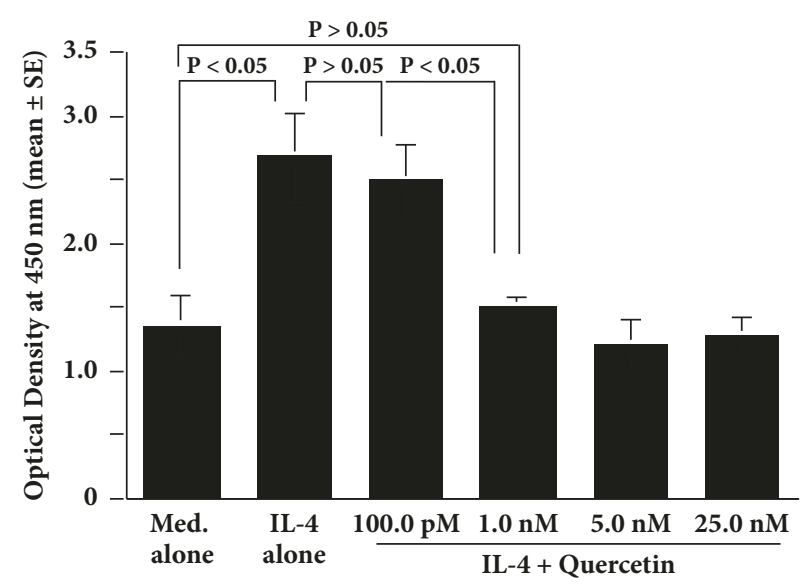

FIGURE 5: Influence of quercetin on STAT6 activation in HNEpCs after IL-4 stimulation in vitro. HNEpCs at $1 \times 10^{5}$ cells/ml are cultured with $10.0 \mathrm{ng} / \mathrm{ml}$ of IL-4 for 12 hours in the presence and absence of various concentrations of quercetin. STAT6 activation is measured using ELISA, and the results are expressed as the mean optical density at $450 \mathrm{~nm} \pm \mathrm{SE}$ of the triplicate cultures. The experiments are performed twice with similar results. Med. alone: medium alone; IL-4: interleukin-4; HNEpCs: human nasal epithelial cells.

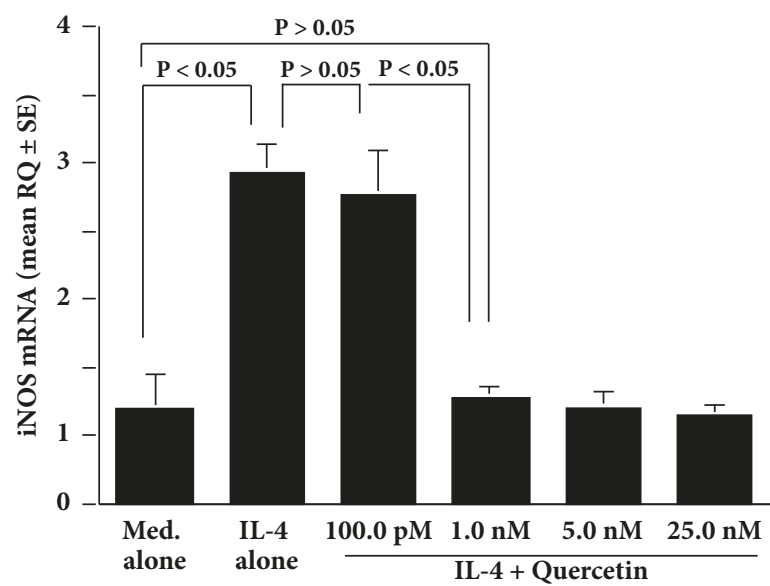

FIGURE 6: Influence of quercetin on iNOS mRNA expression in HNEpCs after IL-4 stimulation in vitro. HNEpCs at $1 \mathrm{x} 10^{5}$ cells $/ \mathrm{ml}$ are cultured with $10.0 \mathrm{ng} / \mathrm{ml}$ of IL-4 for 24 hours in the presence and absence of various concentrations of quercetin. iNOS mRNA expression is measured using quantitative real-time RT-PCR, and the results are expressed as the mean RQ \pm SE of the triplicate cultures. The experiments are performed twice with similar results. Med. alone: medium alone; IL-4: interleukin-4; HNEpCs: human nasal epithelial cells; iNOS: inducible nitric oxide synthase; RQ: relative quantification.

with quercetin at more than $1.0 \mathrm{nM}$. There is also another possibility that quercetin inhibits the phosphorylation of JAK3, followed by suppression of STAT6 activation and iNOS mRNA expression, resulting in inhibition of $\mathrm{NO}$ production. Further experiments are required to clarify this point.

JAK3 and STAT6 phosphorylation require an increase in intracellular $\mathrm{Ca}^{2+}$ levels $[38,39]$. A previous study reported that quercetin can inhibit the increase in intracellular free $\mathrm{Ca}^{2+}$ levels in human mast cells after inflammatory stimulation in vitro [40]. Quercetin has also been reported to inhibit the phosphorylation of several types of tyrosine kinases that are responsible for transcription factor activation [41, 42]. Based these results, quercetin might inhibit the phosphorylation of tyrosine kinases by inhibiting an increase in $\mathrm{Ca}^{2+}$ levels in nasal epithelial cells after IL-4 stimulation, resulting in suppression of both iNOS production and NO generation. Further experiments are required to clarify this assumption.

\section{Conclusion}

Quercetin exerted inhibitory effects on IL-4-induced NO production in HNEpCs. These findings suggested that the ability of quercetin to suppress NO production from nasal epithelial cells may account, at least in part, for the clinical efficacy of quercetin in AR.

\section{Data Availability}

The data used to support the findings of this study are available from the corresponding author upon request.

\section{Conflicts of Interest}

The authors declare that they have no conflicts of interest in this work. 


\section{References}

[1] R. Pawankar, S. Mori, C. Ozu, and S. Kimura, "Overview on the pathomechanisms of allergic rhinitis," Asia Pacific Allergy, vol. 1, no. 3, pp. 157-167, 2011.

[2] D. H. Broide, "Allergic rhinitis: Pathophysiology," Allergy and Asthma Proceedings, vol. 31, no. 5, pp. 370-374, 2010.

[3] F. Ramirez-Jimenez, G. Pavon-Romero, L. L. Juarez-Martinez, and L. M. Teran, "Allergic rhinitis," Journal of Allergy and Therapy, 2012.

[4] A. B. Kay, "The role of eosinophils in the pathogenesis of asthma," Trends in Molecular Medicine, vol. 11, no. 4, pp. 148152, 2005.

[5] A. Min, Y. A. Lee, K. A. Kim, J. El-Benna, and M. H. Shin, "NOX2-derived ROS-mediated surface translocation of BLT1 is essential for exocytosis in human eosinophils induced by LTB 4," International Archives of Allergy and Immunology, vol. 165, no. 1, pp. 40-51, 2014.

[6] P. Pacher, J. S. Beckman, and L. Liaudet, "Nitric oxide and peroxynitrite in health and disease," Physiological Reviews, vol. 87, no. 1, pp. 315-424, 2007.

[7] J. Taira, E. Tsuchida, M. C. Katoh, M. Uehara, and T. Ogi, "Antioxidant capacity of betacyanins as radical scavengers for peroxyl radical and nitric oxide," Food Chemistry, vol. 166, pp. 531-536, 2015.

[8] Y. Steffen, T. Jung, L.-O. Klotz, T. Schewe, T. Grune, and H. Sies, "Protein modification elicited by oxidized low-density lipoprotein (LDL) in endothelial cells: Protection by (-)-epicatechin," Free Radical Biology \& Medicine, vol. 42, no. 7, pp. 955-970, 2007.

[9] A. Furuya, K. Asano, N. Shoji, K. Hirano, T. Hamasaki, and H. Suzaki, "Suppression of nitric oxide production from nasal fibroblasts by metabolized clarithromycin in vitro," Journal of Inflammation, vol. 7, 2010.

[10] H. Kawamoto, S. Takeno, and K. Yajin, "Increased expression of inducible nitric oxide synthase in nasal epithelial cells in patients with allergic rhinitis," The Laryngoscope, vol. 109, no. 12, pp. 2015-2020, 1999.

[11] M. Unal, "Nitric Oxide in Allergic Rhinitis," Anti-Inflammatory \& Anti-Allergy Agents in Medicinal Chemistry, vol. 7, no. 1, pp. $1-3,2008$.

[12] H. Suojalehto, T. Vehmas, I. Lindström et al., "Nasal nitric oxide is dependent on sinus obstruction in allergic rhinitis," The Laryngoscope, vol. 124, no. 6, pp. e213-e218, 2014.

[13] J. Yoon, Y. J. Choi, and E. Lee, "Allergic rhinitis in preschool children and clinical utility of FeNO," Allergy Asthma and Immunological Review, vol. 9, no. 4, pp. 314-321, 2017.

[14] P. Badorrek, M. Müller, W. Koch, J. M. Hohlfeld, and N. Krug, "Specificity and reproducibility of nasal biomarkers in patients with allergic rhinitis after allergen challenge chamber exposure," Annals of Allergy, Asthma \& Immunology, vol. 118, no. 3, pp. 290-297, 2017.

[15] S. C. Bischoff, "Quercetin: potentials in the prevention and therapy of disease," Current Opinion in Clinical Nutrition \& Metabolic Care, vol. 11, no. 6, pp. 733-740, 2008.

[16] E. Middleton, C. Kandaswami, and T. C. Theoharides, "The effects of plant flavonoids on mammalian cells: implications for inflammation, heart disease, and cancer," Pharmacological Reviews, vol. 52, no. 4, pp. 673-751, 2000.

[17] Y.-B. Yu, H. Miyashiro, N. Nakamura, M. Hattori, and C. P. Jong, "Effects of triterpenoids and flavonoids isolated from Alnus firma on HIV-1 viral enzymes," Archives of Pharmacal Research, vol. 30, no. 7, pp. 820-826, 2007.
[18] M. Harwood, B. Danielewska-Nikiel, J. F. Borzelleca, G. W. Flamm, G. M. Williams, and T. C. Lines, "A critical review of the data related to the safety of quercetin and lack of evidence of in vivo toxicity, including lack of genotoxic/carcinogenic properties," Food and Chemical Toxicology, vol. 45, no. 11, pp. 2179-2205, 2007.

[19] N. Kawada, S. Seki, M. Inoue, and T. Kuroki, "Effect of antioxidants, resveratrol, quercetin, and $\mathrm{N}$-acetylcysteine, on the functions of cultured rat hepatic stellate cells and kupffer cells," Hepatology, vol. 27, no. 5, pp. 1265-1274, 1998.

[20] E. Middleton, "Effect of plant flavonoids on immune and inflammatory cell function," Advances in Experimental Medicine and Biology, vol. 439, pp. 175-182, 1998.

[21] Y.-D. Min, C.-H. Choi, H. Bark et al., "Quercetin inhibits expression of inflammatory cytokines through attenuation of NF- $\kappa \mathrm{B}$ and p38 MAPK in HMC-1 human mast cell line," Inflammation Research, vol. 56, no. 5, pp. 210-215, 2007.

[22] M. Sakai-Kashiwabara, S. Abe, and K. Asano, "Suppressive activity of quercetin on the production of eosinophil chemoattractants from eosinophils in vitro," In Vivo, vol. 28, no. 4, pp. 515-522, 2014.

[23] M. S. Sakai-Kashiwabara and K. Asano, "Inhibitory Action of Quercetin on Eosinophil Activation," Evidence-Based Complementary and Alternative Medicine, vol. 2013, 7 pages, 2013.

[24] F. Shishehbor, L. Behroo, M. G. Broujerdnia, F. Namjoyan, and S.-M. Latifi, "Quercetin effectively quells peanut-induced anaphylactic reactions in the peanut sensitized rats," Iranian Journal of Allergy, Asthma and Immunology, vol. 9, no. 1, pp. 2734, 2010.

[25] Y. Song, C. Qu, K. Srivastava et al., "Food allergy herbal formula 2 protection against peanut anaphylactic reaction is via inhibition of mast cells and basophils," The Journal of Allergy and Clinical Immunology, vol. 126, no. 6, pp. 1208-1217, 2010.

[26] M. Kashiwabara, K. Asano, T. Mizuyoshi, and H. Kobayashi, "Suppression of neuropeptide production by quercetin in allergic rhinitis model rats," BMC Complementary and Alternative Medicine, vol. 16, no. 1, article no. 132, 2016.

[27] K. Siemasko, A. S.-F. Chong, H.-M. Jäck, H. Gong, J. W. Williams, and A. Finnegan, "Inhibition of JAK3 and STAT6 tyrosine phosphorylation by the immunosuppressive drug leflunomide leads to a block in IgG1 production," The Journal of Immunology, vol. 160, no. 4, pp. 1581-1588, 1998.

[28] E. Cheng, X. Zhang, K. S. Wilson et al., "JAK-STAT6 pathway inhibitors block eotaxin-3 secretion by epithelial cells and fibroblasts from esophageal eosinophilia patients: promising agents to improve inflammation and prevent fibrosis in EoE," PLoS ONE, vol. 11, no. 6, p. e0157376, 2016.

[29] T. Okumo, S. Furukawa, K. Asano, H. Kobayashi, and M. Sunagawa, "Suppressive activity of chondroitin sulfate on nitric oxide (NO) production by synoviocytes from knee osteoarthritis in vitro," International Journal of Pharmaceutical Sciences Research, vol. 4, no. 125, 2017.

[30] T. Kato, N. Horie, K. Hashimoto et al., "Effect of itraconazoles on the production of pro-inflammatory substances in mouse macrophage-like cells," In Vivo, vol. 24, no. 5, pp. 709-714, 2010.

[31] E. Swartzman, M. Shannon, P. Lieu et al., "Expanding applications of protein analysis using proximity ligation and qPCR," Methods, vol. 50, no. 4, pp. S23-S26, 2010.

[32] C. C. Barbacioru, Y. Wang, R. D. Canales et al., "Effect of various normalization methods on Applied Biosystems expression array system data," BMC Bioinformatics, vol. 7, article 533, 2006. 
[33] J. P. Kósa, A. Kis, K. Bácsi et al., “The protective role of bone morphogenetic protein-8 in the glucocorticoid-induced apoptosis on bone cells," Bone, vol. 48, no. 5, pp. 1052-1057, 2011.

[34] P. C. H. Hollman, M. V. D. Gaag, M. J. B. Mengelers, J. M. P. Van Trijp, J. H. M. De Vries, and M. B. Katan, "Absorption and disposition kinetics of the dietary antioxidant quercetin in man," Free Radical Biology \& Medicine, vol. 21, no. 5, pp. 703707, 1996.

[35] T. A. Wynn, "Type 2 cytokines: mechanisms and therapeutic strategies," Nature Reviews Immunology, vol. 15, no. 5, pp. 271282, 2015.

[36] C. K. Oh, G. P. Geba, and N. Molfino, "Investigational therapeutics targeting the IL-4/IL-13/STAT-6 pathway for the treatment of asthma," European Respiratory Review, vol. 19, no. 115, pp. 4654, 2010.

[37] L. S. Poritz, W. J. Zhang, J. Thompson, M. Boyer, C. Clark, and W. A. Koltun, "Impaired IL-4 phosphorylation of STAT6 in EBV transformed B-cells," Journal of Surgical Research, vol. 162, no. 2, pp. 290-298, 2010.

[38] J. Pan, K. Fukuda, M. Saito et al., "Mechanical stretch activates the JAK/STAT pathway in rat cardiomyocytes," Circulation Research, vol. 84, no. 10, pp. 1127-1136, 1999.

[39] Y. Chiba, M. Todoroki, Y. Nishida, M. Tanabe, and M. Misawa, "A novel STAT6 inhibitor AS1517499 ameliorates antigeninduced bronchial hypercontractility in mice," American Journal of Respiratory Cell and Molecular Biology, vol. 41, no. 5, pp. 516-524, 2009.

[40] S.-H. Kim, C.-H. Choi, S.-Y. Kim, J.-S. Eun, and T.-Y. Shin, "Anti-allergic effects of Artemisia iwayomogi on mast cellmediated allergy model," Experimental Biology and Medicine, vol. 230, no. 1, pp. 82-88, 2005.

[41] D. A. Shoskes, S. I. Zeitlin, A. Shahed, and J. Rajfer, "Quercetin in men with category III chronic prostatitis: a preliminary prospective, double-blind, placebo-controlled trial," Urology, vol. 54, no. 6, pp. 960-963, 1999.

[42] J.-C. Chen, F.-M. Ho, P.-D. L. Chao et al., "Inhibition of iNOS gene expression by quercetin is mediated by the inhibition of I $\kappa$ B kinase, nuclear factor-kappa B and STAT1, and depends on heme oxygenase-1 induction in mouse BV-2 microglia," European Journal of Pharmacology, vol. 521, no. 1-3, pp. 9-20, 2005. 


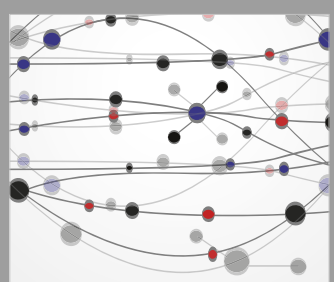

The Scientific World Journal
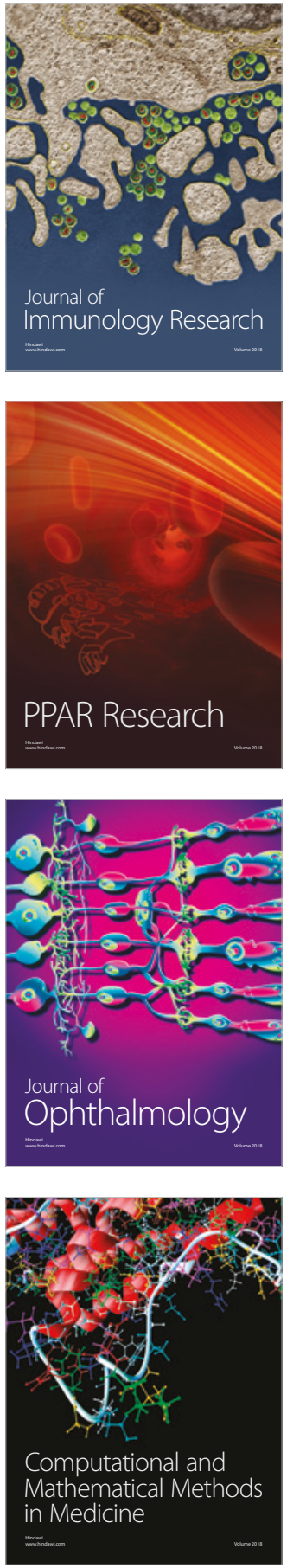

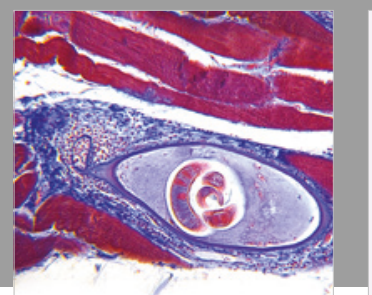

Gastroenterology Research and Practice

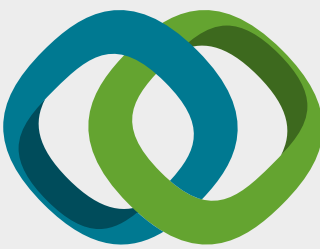

\section{Hindawi}

Submit your manuscripts at

www.hindawi.com
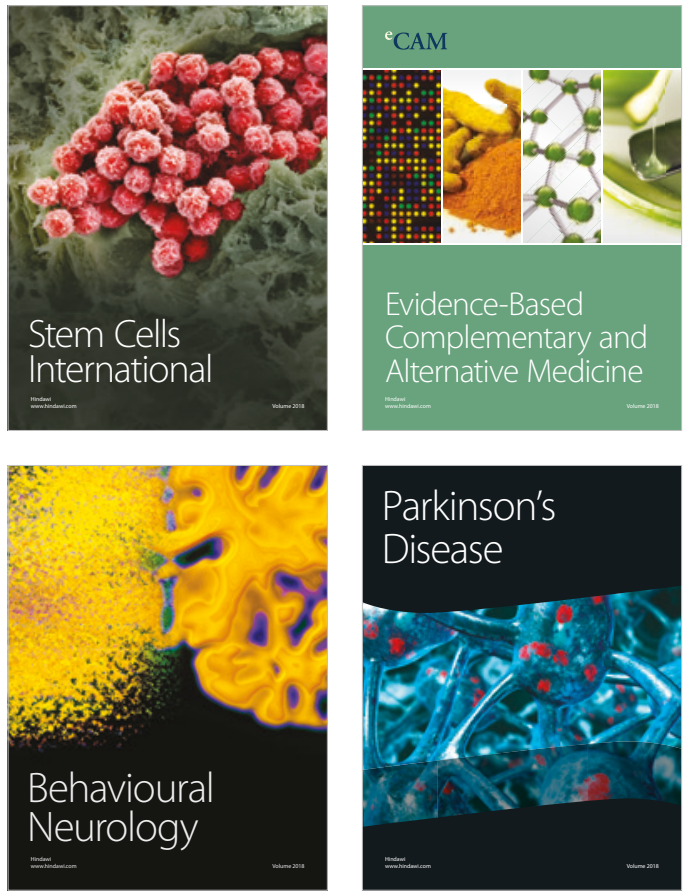

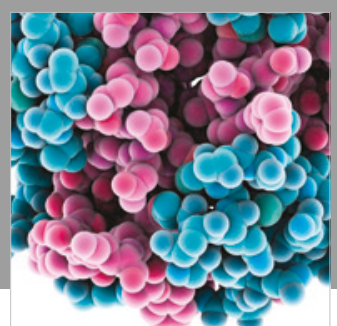

ournal of

Diabetes Research

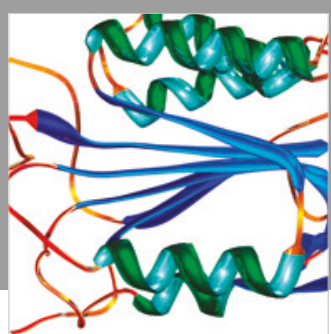

Disease Markers
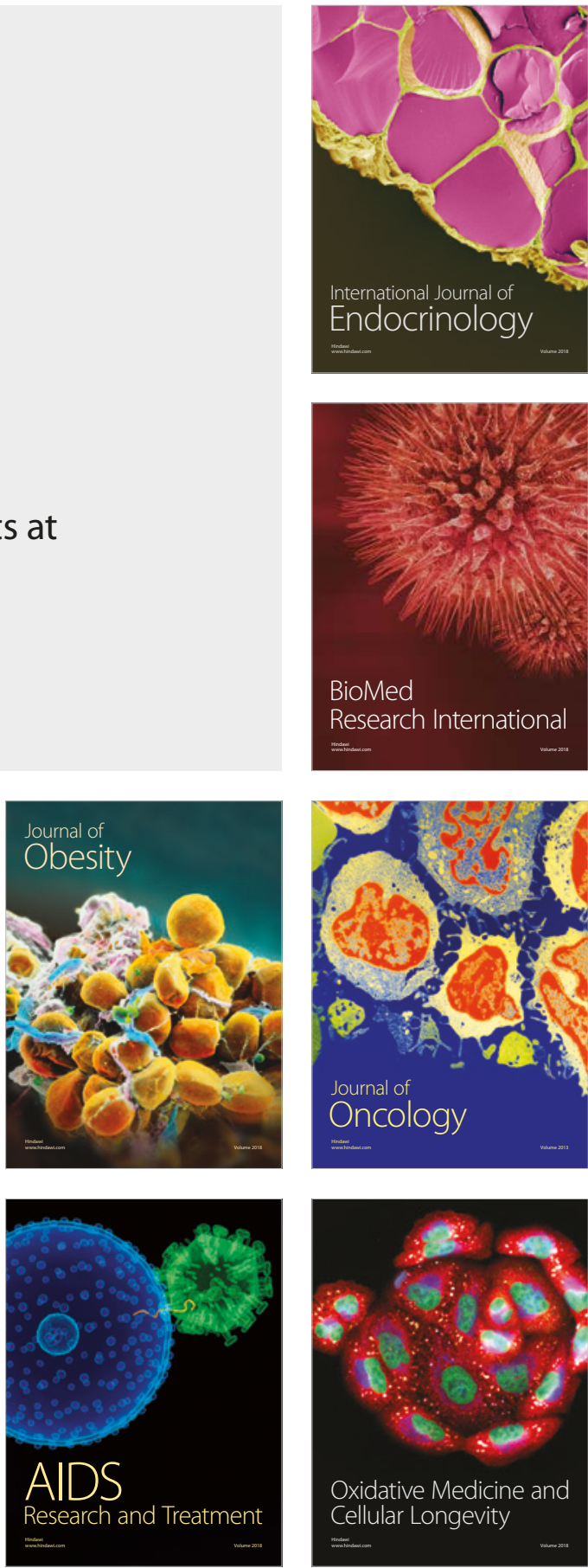